DOI 10.37882/2223-2974.2020.12-2.09

\title{
СТРАТЕГИИ ИННОВАЦИОННЫХ ПРЕДПРИЯТИЙ В УСЛОВИЯХ ИМПОРТОЗАМЕЩЕНИЯ
}

\section{STRATEGIES OF INNOVATIVE ENTERPRISES IN THE CONDITIONS OF IMPORT SUBSTITUTION}

\section{A. Ovchinnikov}

Summary: The article discusses the strategic priorities of the innovative development of the economy in the context of import substitution. The external and internal factors influencing the choice of the strategy of an innovative enterprise in the context of import substitution are listed. The features of the implementation of innovative strategies in the context of import substitution are characterized.

Keywords: import substitution, innovation, innovation strategies.

\author{
Овчинников Алексей Павлович \\ К.э.н., дочент, Российский университет \\ транспорта (МИИТ) \\ alexovchinnikov@mail.ru
}

Аннотация: В статье рассматриваются стратегические приоритеты инновационного развития экономики в условиях импортозамещения. Перечислены внешние и внутренние факторы, влияющие на выбор стратегии инновационного предприятия в условиях импортозамещения. Охарактеризованы особенности осуществления инновационных стратегий в условиях импортозамещения.

Ключевые слова: импортозамещение, инновации, инновационные стратегии.

- организация выпуска продукции энергетического машиностроения;

- организация выпуска информационно-программного обеспечения и др.

Таким образом, в новых условиях ключевая роль в реализации задач стратегии импортозамещения отводится инновационно ориентированным предприятиям. В свою очередь эффективность достижения поставленных задач будет во многом определяться выбранными стратегиями развития инновационных предприятиях в новых условиях.

Проблемы эффективности стратегии импортозамещения и ее результатов на макроуровне рассматривались в различных исследованиях. Выделенные в монографии С.Д. Бодрунова[4] отрасли промышленности, которые рассматриваются в качестве ключевых направлений реализации, либо требуют существенного «инновационного вмешательства», либо сами являются источником инновационного развития для других отраслей: машиностроение, станкостроение, фармацевтическая отрасль, производство медицинской техники и оборудования, выпуск сельскохозяйственной продукции, текстильная промышленность, сектор IT-технологий. В другой коллективной монографии также подчеркивается роль инновационных технологий в отраслевом развитии России на основе стратегии импортозамещения [7]. Проблемы и перспективы стратегии импортозамещения рассматривались и в ряде других монографий $[5,11,15,16]$ и публикаций в периодических изданий[2,13,14].

Стратегии инновационных предприятий - также до- 
вольно развитое направление научных исследований $[6,8]$. Вопросам же выбора стратегий инновационных предприятий в сложившихся условиях в силу относительной новизны направления уделено меньше внимания. Например, Н.В. Стрельцова рассматривает стратегические приоритеты развития российских предприятий в условиях импортозамещения [18]. Группа исследователей рассматривает отдельные аспекты стратегического планирования предприятий в условиях импортозамещения [3]. В статье М.В. Козлова рассматриваются возможности использования частных стратегий вертикального и горизонтального слияния для малых инновационных предприятий в условиях импортозамещения [9]. В другом исследовании раскрыты принципы и составляющие модели, формирующей стратегию развития инновационного предприятия в условиях импортозамещения [12]. Некоторое внимание также уделено вопросам влияния макроэкономических механизмов на выбор стратегии импортозамещения [10].

С точки зрения теоретического обеспечения, выбор и формирование стратегий инновационных предприятий в условиях импортозамещения основываются на методологии менеджмента и его разделов: инновационного менеджмента и менеджмента инноваций, инновационного маркетинга и маркетинга инноваций. С практической стороны, выбор стратегии инновационного предприятия в условиях импортозамещения определяется влиянием большого количества факторов.

В частности, выбор конкурентной стратегии инновационного предприятия в условиях импортозамещения будет определяться влиянием факторов внешнего и внутреннего свойства. К внешним факторам, влияющим на выбор стратегии инновационного предприятия можно отнести:

1. Отраслевые особенности и состояние конкуренции в конкретной отрасли:

- влияние потенциальных покупателей инновационной продукции;

- влияние на конкурентные условия поставщиков;

- структура будущих конкурентных отношений в отрасли;

- вероятность появления аналогичной инновационной продукции как в стране, так и из «дружественных» стран, выделенных условно при осуществлении государственной политики импортозамещения;

- общая вероятность появления нового инновационного предприятиями на рынке инновационного продукции.

2. Состояние государственного регулирования и государственной политики в отрасли, в которой функционирует предприятие:
- наличие или отсутствие различных форм государственной поддержки: финансовой, материальной, налоговой и других форм;

- состояние государственного регулирования отрасли;

- качество законодательства;

- перспективы развития государственной политики в отрасли.

3. Совокупность научно-технических факторов и состояния национальной инновационной инфраструктуры:

- степень распространения инновационных технологий;

- доступность инновационных технологий;

- доступность объектов инновационной инфраструктуры;

- объемы государственного финансирования инновационной инфраструктуры.

Выбор стратегии инновационного предприятия в условиях импортозамещения будет определяться и внутренними факторами. В их числе можно выделить:

1. Тип инновационного предприятия в зависимости от его масштабов (крупное, среднее или малое) будет во многом определять стратегию его развития.

2. Сложившаяся структура отношений с ключевыми заинтересованными группами: потребителями, поставщиками и др.

3. Цели в отношении разрабатываемой инновационной продукции.

4. Рыночное положение инновационного предприятия.

5. Опыт разработки стратегий в целом и стратегий в условиях импортозамещения, в частности.

6. Доступ инновационного предприятия к ресурсам: финансовым, трудовым, материальным, информационным, инновационным.

В самом общем плане можно выделить несколько стратегий инновационных предприятий, принятых в научной литературе, которые могут использоваться и в условиях импортозамещения. Следует учитывать некоторые особенности реализации таких стратегий в условиях импортозамещения. К ним относят [1]:

1. Наступательная стратегия. Для данного вида стратегии характерны высокий уровень риска и потенциальная результативность. Научные исследования и опытно-конструкторские работы (НИОКР) ведутся в сочетании с использованием передовых инновационных технологий. В условиях импортозамещения применение данной стратегии имеет несколько ограничений, связанных с потребностью в специалистах высокой квалификации и доступе к новейшим технологиям. Такой тип стра- 
тегии могут применять крупнейшие российские монополии, ориентирующие свои инновационные подразделения на нужды отраслей экономики. В некоторых случаях, в зависимости от содержания инновационного проекта, наступательная инновационная стратегия может применяться и средними предприятиями.

2. Для другого типа стратегии, оборонительной, характерны относительно низкий уровень риска, рыночные достижения (в виде доли рынка инновационной продукции) и высокий уровень НИОКР. Применение данного типа стратегии уместно для ситуаций с уже имеющимися рынками инновационной продукции, которые высвободились в результате ухода с них зарубежных компаний. К таким производствам можно отнести выпуск медицинской техники и оборудования, производство комплектующих для компьютерной техники и др.

3. Уход с российского рынка зарубежных компаний вследствие осуществления импортозамещения позволяет использовать и промежуточные инновационные стратегии. В рамках данной стратегии инновационное предприятие заполняет пробелы, образованные как результат узкой специализации других предприятий.
4. Актуальной в условиях импортозамещения можно признать стратегию лицензирования (поглощения). Данная стратегия предполагает возможность использования лицензий других предприятий, преимущественно зарубежных.

5. Другой стратегией, использование которой должно учитывать существующие ограничения, является имитационная стратегия. Выбор такой стратегии означает использование предприятием уже обращающихся на рынке инновационных решений с определенной модернизацией и усовершенствованиями.

Перечисленные стратегии инновационных предприятий не исчерпывает перечень их возможных видов. В условиях импортозамещения конфигурация стратегической деятельности предприятия будет определяться значительным множеством внешних и внутренних факторов. Так, предприятие, для которого самой эффективной будет наступательная стратегия может не иметь возможности реализовать данный вид стратегии в силу недостатка финансовых ресурсов. Таким образом, при выборе стратегий в условиях импортозамещения требуется учитывать большое количество факторов, что в свою очередь создает необходимость построения методологических основ выбора эффективных стратегий инновационных предприятий.

\section{ЛИТЕРАТУРА}

1. Агарков С.А. Инновационный менеджмент и государственная инновационная политика / С.А. Агарков, Е.С. Кузнецова, М.0. Грязнова. - Москва: Акад. естествознания, 2011. - 143 С.

2. Бажанов В.А., Орешко И.И. Обрабатывающие производства России: санкции, импортозамещение // ЭК0. - 2019. - № 1 (535). - С. 75-92.

3. Банк С.В., Вилисов В.Я., Христофорова И.В. Формирование инновационных товарных стратегий в условиях импортозамещения // Вопросы региональной экономики. - 2016. - № 1 (26). - С. 3-7.

4. Бодрунов С.Д. Теория и практика импортозамещения: уроки и проблемы / монография / С.Д. Бодрунов. - СПб.: ИНИР им. С.Ю. Витте, 2015. - 171 с.

5. Глаголев С.Н. Импортозамещение в экономике России: монография / С.Н. Глаголев, В.В. Моисеев. - Белгород : Изд-во БГТУ, 2015. - 275 С.

6. Ефимычев Ю.И., Трофимов О.В. Концептуальные основы стратегии инновационного развития промышленных предприятий: Монография. - Н. Новгород: Изд-во ННГУ им. Н.И. Лобачевского, 2010. - 273 с.

7. Импортозамещение в АПК России: проблемы и перспективы: монография. - М.: ФГБНУ «Всероссийский НИИ экономики сельского хозяйства» (ФГБНУ ВНИИЭСХ), 2015. -447 c.

8. К Касс М.Е. Формирование стратегии инновационного развития предприятия на основе управления нематериальными активами [Текст]: монография / М.Е. Касс; Нижегор. гос. архитектур.- строит. ун-т - Н.Новгород: ННГАСУ, 2011. - 159 с.

9. Козлов М.В. Вертикальное и горизонтальное объединение в кластер как стратегия импортозамещения для малого инновационного предприятия // Экономика и современный менеджмент: теория и практика. - 2015. - № 46. - С. 40-49.

10. Коновалов Ю.В. Механизмы промышленной политики, влияющие на импортозамещение и инновационную стратегию предприятий // Российское предпринимательство. - 2017. - Т. 18. № 6. - С. 957-970.

11. Концепция импортозамещения продукции легкой промышленности: предпосылки, задачи, инновации : [монография] / В.Т. Прохоров, Т.М. Осина, Д.В. Рева [и др.]. - Новочеркасск : Лик, 2017. - 334 с.

12. Кузнецов И.М. Организационно-экономические модели формирования стратегии инновационного производства электрооборудования в условиях импортозамещения // Транспортное дело России. - 2016. - № 2. - С. 3-5.

13. Лифшиц А.М., Менделевич В.А. Круглый стол «импортозамещение - драйвер развития цифровой энергетики, мифы или реальность» // Автоматизация и ІТ в энергетике. - 2020. - № 11 (136). - С. 68-70.

14. Оборин М.С. Проблемы и перспективы импортозамещения в отрасли сельского хозяйства // Ученые записки Крымского федерального университета 
имени В.И. Вернадского. Экономика и управление. - 2020. Т. 6. - № 2. - С. 96- 105.

15. Осташевский С.М. Теоретико-методологические аспекты импортозамещения как фактора повышения эффективности российской экономики : монография / С.М. Осташевский. - Москва ; Челябинск : Изд-во ЧоУВО РБИУ, 2017. - 158 с.

16. Пичурин И.И. Особенности промышленного маркетинга в России на этапе импортозамещения : монография / И.И. Пичурин. - Екатеринбург : Изд-во УМЦ УПИ, 2015. - 183 с.

17. Постановление Правительства РФ от 15 апреля 2014 г. N 328 "0б утверждении государственной программы Российской Федерации "Развитие промышленности и повышение ее конкурентоспособности" (с изменениями и дополнениями) / Гарант. URL: https://base.garant.ru/70643464/\#friends (дата обращения: 12.11.2020).

18. Стрельцова Н.В. Развитие инновационного потенциала российских предприятий в условиях государственной политики импортозамещения // Экономика и социум. - 2014. - № 4-6 (13). - С. 938-947.

(c) Овчинников Алексей Павлович (alexovchinnikov@mail.ru).

Журнал «Современная наука: актуальные проблемы теории и практики»

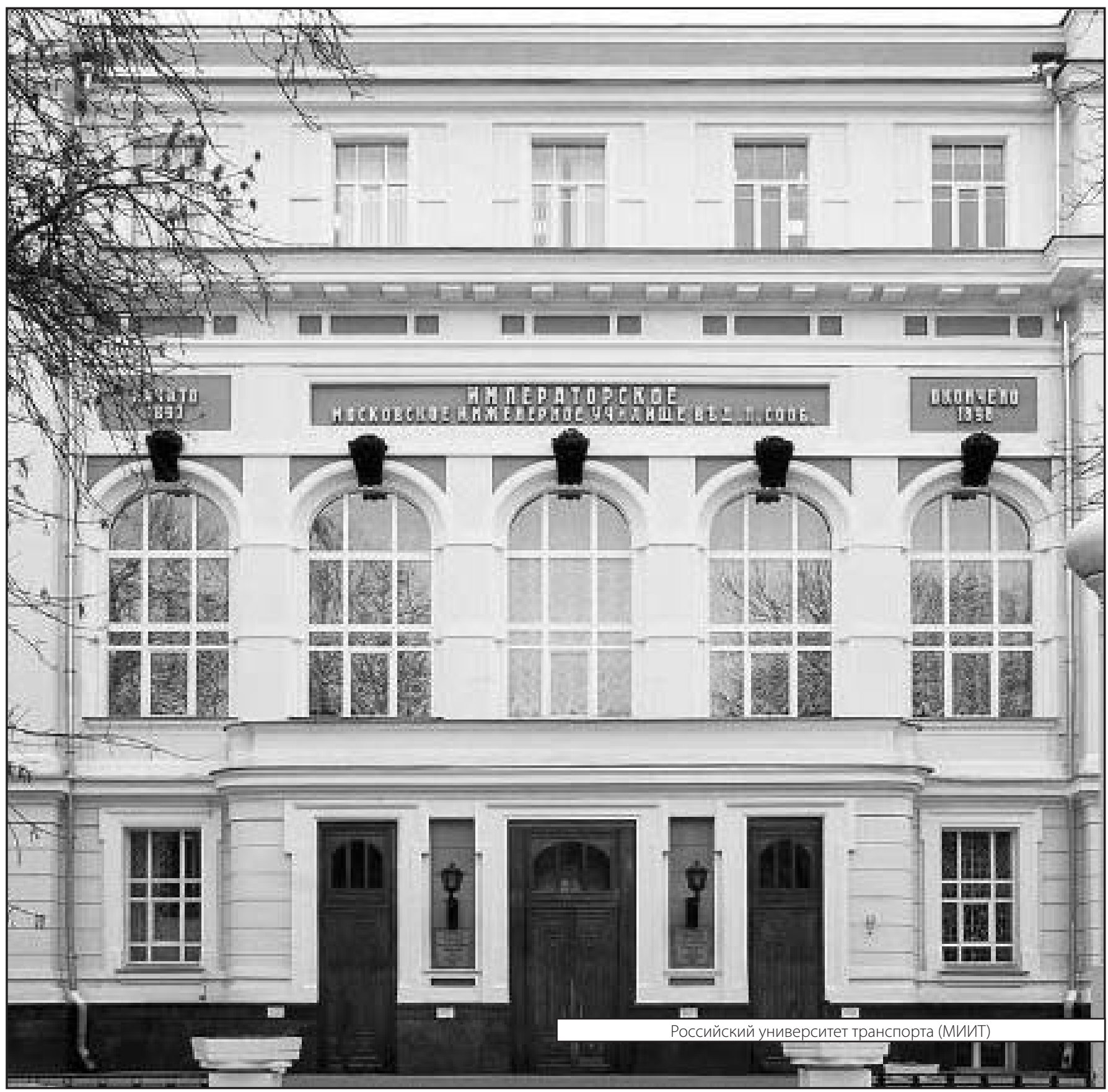

